\title{
Exploring Saudi Citizens' Acceptance of Mobile Government Service
}

\author{
Dr. Adnan Mustafa AlBar, Mashael A. Hddas \\ Department of Information Systems \\ Faculty of Computing \& Information Technology \\ King Abdulaziz University, Jeddah, Saudi Arabia
}

\begin{abstract}
Mobile government is considered as an emerging technology that has been used in Saudi Arabia in order to enhance communication between the government and its citizens, it can also be considered as a mechanism through which the government can effectively respond to their needs and expectations. The current study seeks to propose and validate $M$ government adoption model to fully understand the varied variables affecting the adoption behavior. This model is based on Technology Acceptance Model (TAM) and DeLone and McLean Information Systems Success Model. The researchers will depend on a descriptive survey approach using structured questionnaires to investigate the extent of M-government acceptance by Saudi users. Structural equation modeling will be used as a method for statistical data analysis.
\end{abstract}

\section{Keywords-M-government; adoption; acceptance; citizen}

\section{INTRODUCTION}

There is no doubt that the developed technology has permeated all walks of life, which has helped in doing things more easily than ever before, this in fact has had a great impact on many aspects of our lives such as health, education, transportation and communication.

The development in the field of technology has led to the introduction of many advanced tools that have a lot of useful applications for better communication. Nowadays, smart devices, iPhone and tablets have become important mechanisms for communication [1]. The wide spread of mobile devices around the world and the technological revolution surrounding their different applications have opened the floodgates for the introduction of M-government [2-3].

\section{RESEARCH Motivation}

Despite the fact that Kingdom of Saudi Arabia has made significant strides in the field of technological infrastructure development, M-government technology is still in its infancy, this confirms the idea that the Saudi government should pay more attention to integrate M-government services in its public sector in order to achieve its national objectives and reduce constraints imposed on citizens as a result of using traditional government services [4-5]. My research is motivated by the urgent desire to investigate the different factors that may affect the acceptance of M-government in Saudi Arabia through combining the dimensions of DeLone and McLean success model represented in (system quality, information quality and service quality) with the dimensions of TAM model represented in (Perceived Usefulness and Perceived Ease of Use) to determine their effects on attitudes, behavior intentions and actual use of the system. . Worthy here to mention that using the two models will enable the researchers to make full use of the strength areas of these models and as a result draw a full picture of the factors that affect M-government acceptance behavior among Saudi citizens. Identifying these factors can be considered as a must in order to move from the preliminary phase of experimentation to the actual use of the system for maximizing the benefits that can be gained from applying Mgovernment in Saudi Arabia. Finally, the current study will provide some suggestions to help policy makers in improving the system of M-government in Saudi Arabia.

\section{SIMILAR WORK}

In a study [6] that has been carried out to investigate factors relevant to diffusion and adoption of M- Government in Greece, findings revealed that ease of use and compatibility could affect the adoption behavior. Another study [7] has been conducted to determine issues surrounding M-government services adoption in Jordon, results showed that public awareness, infrastructural limitations and lack of comprehensive legal framework were among the critical issues surrounding the use of M-government. At the local level a study has been conducted [8] to determine variables affecting M-government adoption in Saudi Arabia, findings revealed that satisfaction, mobility and trust were predictors of adoption behavior among citizens. Another study [9] analyzed the challenges and opportunities associated with the implementation of m-government services in Saudi Arabia. The results suggested that although a large percentage of population did not have access to mobile technologies, there was still a strong desire among users for the provision of Mgovernment services. The previous studies and researches mentioned above have revealed that M-government technology is affected by varied factors. In order to identify these factors; the researchers will make full use of the three major dimensions of the DeLone and McLean Success Model (system quality, information quality and service quality) and two dimensions of the TAM Model (represented in perceived usefulness and perceived ease of use) to determine their effects on attitudes, behaviour intentions and use of Mgovernment system in Saudi Arabia. This mixing between the two models in fact will be of great significance as it enables the researchers to combine the most common factors that can affect acceptance of M-government in Saudi Arabia. 


\section{E-GOVERNMENT AND M-GOVERNMENT IN SAUDI} ARABIA

All e. government initiatives issued by the Saudi government can be considered as a part of its National Information Technology plan in an attempt to restructure different processes taken place in the public sector [10]. Mobile government technology is still in the initial phase, this confirms the idea that the Saudi government should pay more attention to integrate M-government services in its public sector to generalize this experience all through the kingdom [11].

The study of M-government adoption behavior among Saudi citizens is of great importance as it helps us in identifying the different opportunities and challenges face the industry of M-government and as a result it will help in improving this service through getting a closer look on the different behaviors of Saudi citizens especially while taking into consideration the different challenges associated with Mgovernment adoption such as security, privacy, usability and so on. In addition, the most important challenge that hinders the effective implementation of M-government lies in the adoption behavior of citizens, some researchers agreed that the Saudi government needs to overcome different inequalities that impede the effective adoption of M-government services [12].

\section{THEORY BACKGROUND}

The advancement in wireless communication has paved the way to the emergence of M-government. M-government can be seen as an effective and efficient solution for delivering services using mobile technology [2-13]. The goals and objectives of M-government are diverse including -but not limited to- saving time, cost and effort through providing efficient services to citizens using electronic channels [14]. It also aims at enhancing civic engagement among citizens [15] Many countries seek to implement M-government initiatives. The point of departure here is that the implementation of Mgovernment heavily depends on many variables among them is the adoption behavior of citizens [16-17].

\section{QUESTIONNAIRE}

The researchers designed a structured questionnaire that would be used to reflect users' views regarding the critical factors that might affect the behavior intention and attitudes towards M-government, the dimensions of the questionnaire will be extracted from a model designed by the researchers through making full use of dimensions of DeLone and McLean Information Systems Success model and TAM model. The questionnaire consisted of three main parts: The first part was dedicated to gather demographic information related to gender, age, educational level, employment status, ICT usage experience and the actual use of M-government services. The second part included eight main dimensions represented in system quality, information quality, service quality, perceived usefulness, perceived ease of use, attitudes, actual use and behaviour intention. The final part included open questions to identify the different strategies that could be used or added to improve the quality of services being provided. The current questionnaire has Arabic and English versions. It depended on a 5-point Likert scale ranging from strongly disagree to strongly agree.

\section{DATA COLLECTION}

The researchers will depend on the descriptive survey approach as the main study approach. Descriptive survey approach is concerned with the characteristics of whole sample of the study in an attempt to provide effective solutions to the problem. The survey approach makes full use of scientific methods by examining the different materials, analyzing data and reaching some results that can be generalized [18]. Online Surveys will be used to gather quantitative data for the proposed theoretical model in an attempt to reach as many people as possible. Surveys will be emailed to public and private organizations requesting them to forward these questionnaires to their employees. It will also be sent to universities to ask students and academic staff to participate in the survey, this process succeeded in gathering the responses from 1218 participants in the study.

\section{DATA ANALYSIS}

Microsoft Excel was used to code the data. In this step, we identified the variables of the study, the columns they occupied in the data file, their possible values. The five-point Likert scale was coded with values ranging from (Strongly Disagree $=1$, Disagree $=2$, Neutral=3, Agree= 4, and Strongly Agree $=5$ ). In order to test hypotheses and analyze data required for the current study, the researchers used Structural Equation Modeling (SEM) technique as the main instrument used in the analysis. It is a powerful multivariate analysis used to test the validity of hypothesized theoretical models. It can also be seen as a simple method to show numerous relationships simultaneously and evaluate relationships [19]. The analysis will be done using SmartPLS software. PLS is a SEM technique that simultaneously represents the theoretical relationship among latent variables and the relationships between latent variables and their indicators. The software package SmartPLS version 2 for SEM analysis and SPSS version 21 for descriptive analysis of demographic information would be used. The data set would be evaluated for missing values, invalid observations or outliers. When missing data for an observation exceeded $15 \%$, it will be removed from the data set. When less than $5 \%$ of values per indicator would be missed, mean value replacement would be used. Otherwise, case-wise deletion would be used. After identifying outliers, they would be removed from the data if they represented less than 5\% [20]. The path coefficients and the coefficients significance were used for hypotheses testing. Hypotheses testing in SmartPLS could be involved in the evaluation of $\mathrm{t}$-values. All $\mathrm{p}$ significance levels $(\mathrm{p}<0.01$, $p<0.05$ and $p<0.10)$ were addressed. The larger $p$ value of less than 0.10 could be regarded as appropriate for exploratory research [20].

\section{Discussion OF RESUlTS}

The descriptive statistics of the study showed that (52.6\%) of the study sample were males while $(47.4 \%)$ were females. The majority of the participants' ages ranged from 20 to 29 years old, they had good knowledge of ICT, most of them used ICT applications for less than one hour a day and they 
had been using mobile phones for more than five years. The majority of them used mobile phones in order to make calls and send messages and most of them use M-government services for many different reasons, but the most prominent one was to obtain applications from the Ministry of Education. The results of the study showed that System Quality and Information Quality had not statistical significant effects on Perceived Usefulness. This result went in harmony with the results mentioned by [21] who showed that neither system quality nor information quality had positive effects on perceived usefulness. On the contrary, the results confirmed that perceived security had a positive effect on perceived usefulness. Worthy here mentioning that these results were disappointing, especially while keeping in mind that the researchers had expected that system quality and information quality could play critical roles in affecting perceived usefulness as our beliefs regarding the feasibility of a system could be formed in the light of the quality of the system as a whole and the quality of the information being provided by it. Information quality, service quality and perceived usefulness had positive effects on the perceived ease of use. Also, Service quality had a positive effect on perceived usefulness. This result went in harmony with the result of [22] who indicated that services quality (SQ) was found to have the strongest influence on adoption of M-government. Honestly, the researchers expected these results, especially while taking into account that information quality, service quality and perceived usefulness have been shown in the literature to be powerful factors that have the ability to influence M-government adoption behaviour. The results of the study showed that perceived ease of use and perceived usefulness had positive effects on attitudes towards M-government; the results were consistent with [23] who showed that perceived ease of use, near-term usefulness and long-term usefulness had significant and positive influences on the intention to use mobile government. These results were not consistent with [24] who showed that perceived usefulness had a positive effect on perceived value. Attitudes had positively affected behavior intention. This result went in harmony with [24] who showed that individual's intention to behave was based on the person's attitude. Behavior intention had positively affected actual use of M- government. This result went in harmony with the theory of reasoned action [25] indicating that one's intentions affected his actual behavior. Here the behaviour component can be seen as a driving force towards using M-government services, and as a result, once behaviour intention was motivated, actual use could be guaranteed. Significant testing of results using structural model path coefficients can be shown as in the following table:

Based on their sizes, the results showed that SeQ had the strongest effect on PU (0.5479), followed by PEOU (0.1776), while SQ, and IQ almost had no effect. Also, SeQ had a strong effect on PEOU (0.4048), followed by IQ (0.2635) and SQ (0.1406). Findings showed that both PU (0.5497) and PEOU (0.3041) had strong effects on Att. Also, these findings showed that Att had strong effect on BI (0.6086), and BI had a strong effect on AU (0.5799). The Path Coefficients can be shown as in the following table:
TABLE I. SUMMARY OF SIGNIFICANT TESTING OF RESUlts

\begin{tabular}{|l|l|l|l|l|}
\cline { 2 - 5 } \multicolumn{1}{l|}{} & $\begin{array}{l}\text { Path Coefficient } \\
\text { (Bootstrap) }\end{array}$ & $\begin{array}{l}\text { tt- } \\
\text { values }\end{array}$ & PP- value & $\begin{array}{l}\text { Significance } \\
\text { Levels }\end{array}$ \\
\hline $\mathrm{SQ} \rightarrow \rightarrow \mathrm{PU}$ & 0.0485 & 1.22 & 0.22 & $N S$ \\
\hline $\mathrm{SQ} \rightarrow \rightarrow \mathrm{PEOU}$ & 0.1408 & 3.66 & $<0.001$ & $* * *$ \\
\hline $\mathrm{IQ} \rightarrow \rightarrow \mathrm{PU}$ & -0.0703 & 1.61 & 0.11 & $N S$ \\
\hline $\mathrm{IQ} \rightarrow \rightarrow \mathrm{PEOU}$ & 0.2638 & 6.06 & $<0.001$ & $* * *$ \\
\hline $\mathrm{SeQ} \rightarrow \rightarrow \mathrm{PU}$ & 0.5493 & 11.89 & $<0.001$ & $* * *$ \\
\hline $\mathrm{SeQ} \rightarrow \rightarrow \mathrm{PEOU}$ & 0.4061 & 9.72 & $<0.001$ & $* * *$ \\
\hline $\mathrm{PEOU} \rightarrow \rightarrow \mathrm{PU}$ & 0.1773 & 4.20 & $<0.001$ & $* * *$ \\
\hline $\mathrm{PEOU} \rightarrow \rightarrow$ Att & 0.3053 & 9.66 & $<0.001$ & $* * *$ \\
\hline $\mathrm{PU} \rightarrow \rightarrow$ Att & 0.5497 & 21.06 & $<0.001$ & $* * *$ \\
\hline $\mathrm{Att} \rightarrow \rightarrow \mathrm{BI}$ & 0.6105 & 25.76 & $<0.001$ & $* * *$ \\
\hline $\mathrm{BI} \rightarrow \rightarrow$ AU & 0.5819 & 22.73 & $<0.001$ & $* * *$ \\
\hline & & & $* \mathrm{p}<0.10 . * * \mathrm{p}<0.05 . * * * \mathrm{p}<0.01$. \\
\hline
\end{tabular}

TABLE II. PATH COEFFICIENTS

\begin{tabular}{|l|l|l|l|l|l|}
\hline & PU & PEOU & Att & BI & AU \\
\hline SQ & 0.0479 & 0.1406 & & & \\
\hline IQ & -0.0695 & 0.2635 & & & \\
\hline SeQ & 0.5479 & 0.4048 & & & \\
\hline PU & & & 0.5497 & & \\
\hline PEOU & 0.1776 & & 0.3041 & & \\
\hline Att & & & & 0.6086 & \\
\hline BI & & & & & 0.5799 \\
\hline
\end{tabular}

\section{Most Prominent Results And ReCOMmendations}

The most important results can be shown as follows: system quality (SQ) has not a positive influence on the Perceived Usefulness (PU) of using M-government, System Quality (SQ) has a positive influence on the Perceived Ease of Use (PEOU) of using M-government, Information Quality (IQ) has not a positive influence on the perceived usefulness of using M-government, Information Quality (IQ) has a positive influence on the Perceived Ease of Use (PEU) of using M-government, Service Quality (SeQ) has a positive influence on the Perceived Usefulness (PU) of using Mgovernment, Service Quality (SeQ) has a positive influence on 
the Perceived Ease of Use (PEU) of using M-government, Perceived Usefulness (PU) has a positive influence on Attitude (Att), Perceived Ease of Use (PEU) has a positive influence on Attitude (Att), Attitude (ATT) has a positive influence on Behaviour Intention (BI) to use M-government services, Behavior Intention (BI) had a positive influence on Actual Use (AU) of M-government. The researchers recommend improving the provision of services being provided by M-government as a mean of improving citizens' attitudes, intention behaviour and actual use of Mgovernment, this can be done by making the governmental website more attractive, easing the browsing process, providing guidelines related to how to deal with the website, building trust in M-government transactions, providing internet connections especially to those in remote areas. The researchers also recommend developing the technological infrastructure within the Kingdom in order to provide citizens with easy access electronic services. Improving the rates of use of M-government will help in reducing the burdens imposed on many governmental agencies.

For future studies, the researchers recommend conducting similar studies but in other regions in Saudi Arabia using different methodological approaches, for example conducting studies using comparative approaches in order to compare levels of acceptance of M-Government Service between Asir and Jeddah to determine levels of acceptance and adoption behaviors and different factors affecting them.

\section{ACKNOWLEDGMENT}

I'd like to thank all researchers in the Department of Information Systems at Faculty of Computing \& Information Technology for their help, I'd like also to thank those who are working at King Abdulaziz University, Saudi Arabia for easing my mission as a researcher especially when conducting the field study.

\section{REFERENCES}

[1] H. Abdelghaffar and Y. Magdy, "The Adoption of Mobile Government Services in Developing Countries: The Case of Egypt," International Journal of Information and Communication Technology Research, vol. 2, pp. 333-341, 2012.

[2] E. Goyal and S. Purhoit, "Emergence of M. Government the way forward," SIES Journal of Management, vol. 8, pp. 56-65, 2012.

[3] V. R. Rao, "Improving Government to Employee (G2E) Services through Mobile Technology - A Survey," International Journal of Computer Applications, vol. 168, pp. 33-45, 2017.

[4] T. Ahmad, A. A. Ansari, A. Akhtar, and S. Parveen, "Current Review Of ICT And M-Government Services In Saudi Arabia," International Journal of Computer Engineering and Applications, vol. VII, pp. 71-77, 2014.

[5] M. Alsenaidy and T. Ahmad, "A review of current state m government in Saudi Arabia," Global engineers \& Technologists Review, vol. 2, pp. 5-8., 2012.

[6] A. Vrechopoulos and M. Batikas, "Predicting the Adoption of Mobile Government Services". In"Mobile and Ubiquitous Commerce: Advanced E-Business Methods", Vol. 4, M. Head,. Eds. IGI Global, 2009, pp. 63-78.

[7] O. Al-Hujran, "Toward The Utilization Of M-Government Services In Developing Countries: A Qualitative Investigation," International Journal of Business and Social Science, vol. 3, pp. 155-160, 2012.

[8] S. Alotaibi and D. R., "A Conceptual Model for Examining Mobile Government Adoption in Saudi Arabia," In: Proceedings of the
European Conference on e-Government, ECEG. Academic Conferences Limited, pp. 369-375, 2015.

[9] A. Alssbaiheen, "M. Government Adoption in Saudi Arabia: Challenges and Opportunities," International Journal of Technology and Human Interaction (IJTHI), vol. 11, 2015, DOI: 10.4018/ijthi.2015070104, Available online at http://www.irma-international.org/article/mgovernment-adoption-in-saudi-arabia/128403/

[10] N. Abanumy and P. J. Mayhew, "M- government Implications For EGovernment In Developing Countries: The Case of Saudi Arabia," Presented at The First European Mobile Government Conference, University of Sussex, Brighton, UK, 2005.

[11] C- M. Park and J- H. Bae, "Sources of Public Trust in Government: East Asian Evidence," Prepared for delivery at the IIAS Study Group on Trust and Public Attitudes Workshop on "Trust in Public Administration" in Seoul, Korea on December 11-12, 2012.

[12] A. Alssbaiheen and S. Love, "The Opportunities and Challenges Associated With M-Government as an E-Government Platform in KSA: A Literature Review," IJMBS, vol. 5, pp. 31-38, 2015.

[13] H. S. Al-Hubaishi, S. Z. Ahmad, and M. Hussain, "Exploring mobile government from the service quality perspective," Journal of Enterprise Information Management, vol. 30, pp. 4-16, 2017.

[14] M. Abaza and F. Saif, "The adoption of mobile government services in developing countries," IJCSI International Journal of Computer Science Issues, vol. 2, pp. 137-145, 2015.

[15] A. S. Albesher, "Civic engagement with traditional government and mobile government: Comparing rural to urban citizens in Saudi Arabia," Doctor Thesis, Iowa State University, Ames, Iowa, 2016.

[16] Y. K. Dwivedi, M. A. Shareef, and N. Archer. "Examining Adoption Behavior Of Mobile Government," The Journal of Computer Information Systems, vol. 53, pp. 39-49, 2012.

[17] S. Rees, "Designing User - Centric Mobile Government: A Checklist for Efficiency and Effectiveness," European Conference on e-Government, vol. 2016, pp. 170-176, 2016.

[18] N. SALARIA, "Meaning Of The Term- Descriptive Survey Research Method," International Journal of Transformations in Business Management, vol. 1, 2012, pp.1-7.

[19] J. C. Anderson and D. W. Gerbing, "Structural equation modeling in practice: A review and recommended two-step approach," Psychological Bulletin, vol. 103, p. 411, 1988.

[20] J. F. Hair, G. T. M. Hult, C. M. Ringle, and M. Sarstedt, A primer on Partial Least Squares Structural Equation Modeling (PLS-SEM). Thousand Oaks, CA: SAGE, 2014.

[21] C. Wang, R. Fang, K. Park, Y. Feng, Z. Lu, and Y. Cui, "Perceived Usefulness, Perceived Security and Adoption of Mobile Government: An Empirical Research," Advances in information Sciences and Service Sciences (AISS), vol. 4, pp. 234-244, 2012.

[22] N. Sahari, N. A. M. Zain, and A. Althunibat, "Modeling the factors that influence mobile government services acceptance," African Journal of Business Management, Vol. 5, pp. 13030-13043, 2011.

[23] Y. Liu, H. Li, V. Kostakos, J. Goncalves, S. Hosio, and F. Hu, "An empirical investigation of mobile government adoption in rural China: A case study in Zhejiang province," Government Information Quarterly, Vol. 31, pp. 432-442, 2014.

[24] T. R. Huggins, C. M. Yates, R. J. Cook., R. B. Tranter, J. R. Park, and P. T. Dorward, "Theory Of Reasoned Action And Its Integration With Economic Modeling In Linking Farmers' Attitudes And Adoption Behavior - An Illustration From The Analysis Of The Uptake Of Livestock Technologies In The South West Of England," International Farm Management Association, 14th Congress, Perth, Western Australia, August 10-15, 2003.

[25] W. Jen, T. Lu and P. T. Liu, "An Integrated Analysis of Technology Acceptance Behavior Models: Comparison of Three Major Models," MIS Review, vol. 15, pp. 89-121, 2009. 